\title{
High Temperature Oxidation Performance of an Additively Manufactured Mo-9Si-8B Alloy
}

\author{
Julia Becker ${ }^{1}$. Sven Schmigalla ${ }^{2}$. Sabine Schultze ${ }^{2}$. \\ Silja-Katharina Rittinghaus ${ }^{3} \cdot$ Andreas Weisheit $^{3} \cdot$ Janett Schmelzer ${ }^{1}$. \\ Manja Krüger ${ }^{1}$
}

Received: 23 February 2021 / Revised: 6 August 2021 / Accepted: 12 August 2021 /

Published online: 12 October 2021

(c) The Author(s) 2021

\begin{abstract}
As reported in previous studies, the processing of $\mathrm{Mo}-\mathrm{Si}-\mathrm{B}$ alloys using additive manufacturing (AM) techniques, like directed energy deposition (DED) shows a high technical feasibility. The present work investigates the cyclic oxidation performance of an AM DED Mo-9Si-8B alloy. Depending on the temperature $\left(800{ }^{\circ} \mathrm{C}\right.$, $1100{ }^{\circ} \mathrm{C}, 1300{ }^{\circ} \mathrm{C}$ ), the oxidation mechanisms vary, which is due to different reactions at the surface of the alloys accompanied with mass changes of samples. These mass changes can be explained on the basis of microstructural investigations. However, compared to a powder metallurgically processed Mo-9Si-8B alloy, the AMDED alloy shows competitive oxidation performance at potential application temperatures of $1100{ }^{\circ} \mathrm{C}$ and $1300{ }^{\circ} \mathrm{C}$, while a catastrophic materials degradation occurs at $800{ }^{\circ} \mathrm{C}$ as also observed in other Mo-rich Mo-Si-B alloys.
\end{abstract}

Keywords Mo-Si-B · Additive manufacturing $\cdot$ Directed energy deposition $\cdot$ Cyclic oxidation

Julia Becker

julia.becker@ovgu.de

$\bowtie$ Janett Schmelzer

janett.schmelzer@ovgu.de

1 Institute of Materials and Joining Technology, Otto-Von-Guericke-University Magdeburg, 39016 Magdeburg, Germany

2 Institut Für Korrosions- Und Schadensanalyse, 39124 Magdeburg, Germany

3 Fraunhofer - Institute for Laser Technology, 52074 Aachen, Germany 


\section{Introduction}

With respect to the thermodynamic efficiency of turbine engines or stationary gas turbines current research on high temperature metallic materials focuses on Mo-Si-B alloys, which are potential candidates for novel turbine materials [1-4]. Those alloys are creep resistant materials for accessing harsh loading scenarios beyond Ni-based superalloys due to their excellent mechanical performance at ultra-high temperatures $\left(>1200{ }^{\circ} \mathrm{C}\right)$. Alloy compositions located within the socalled Berczik-triangle [5] of the ternary Mo-Si-B system offer promising characteristics for the focused applications. The specific combination of three phases, the BCC Mo solid solution phase $\left(\mathrm{Mo}_{\mathrm{ss}}\right)$ and the silicides $\mathrm{Mo}_{5} \mathrm{SiB}_{2}\left(\mathrm{D} 8_{1}\right.$ structure, T2) and $\mathrm{Mo}_{3} \mathrm{Si}$ (A15 type), enables a balanced characteristics for alloys taken from this compositional region. The three-phase microstructure offers a wide stability range up to high temperatures of around $1800{ }^{\circ} \mathrm{C}$ [6] which features a positive effect on the creep resistance. On the one hand, the comparably high amount of $\mathrm{Mo}_{\mathrm{ss}}$ phase (around 50\%) reduces the oxidation resistance, but on the other hand, provides an essential advantage for the room temperature fracture toughness $[7,8]$. In order to find a balance between the "weak" and "strong" microstructural constituents and thus, the resulting properties, it has to be taken into account that the alloy composition as well as the manufacturing technique has an essential influence on the microstructure evolution.

The most widely studied alloy composition of $\mathrm{Mo}-9 \mathrm{Si}-8 \mathrm{~B}$ is able to combine acceptable properties at room temperature (fracture toughness) and excellent high temperature properties (creep and oxidation resistance) [9]. Particularly, when fabricated by powder metallurgical processing the alloy is composed of a continuous solid solution phase $\left(\mathrm{Mo}_{\mathrm{ss}}\right)$ with homogeneously distributed isolated silicide phases: $\mathrm{Mo}_{3} \mathrm{Si}$ and $\mathrm{Mo}_{5} \mathrm{SiB}_{2}$. An important innovation for this type of materials is the introduction of a one-step process via additive manufacturing (AM) which allows the production of complex near-net-shape bulk materials, e.g., turbine blades, as shown in Fig. 1. The feasibility of printing pre-alloyed Mo-Si-B powder materials via Directed Energy Deposition (DED) process was firstly demonstrated on a near-eutectic Mo-13.5Si-7.5B alloy by Schmelzer et al. [10]. For the present article, the alloy composition Mo-9Si-8B, which is known for its excellent property profile, was chosen for processing via AM DED.

As compared to the near-eutectic alloy, the Mo-9Si-8B alloy has a higher melting point of $\sim 2360{ }^{\circ} \mathrm{C}$, which might be challenging with regard to AM processing. Hence, in our previous studies [10,13] the feasibility of processing Mo-9Si-8B, Mo-13.5Si-7.5B and Mo-16.5Si-7.5B alloys via AM process was evaluated by microstructure analysis as well as the correlation of AM microstructures to key mechanical properties. As shown in prior studies, the resulting microstructure has an essential influence on the high temperature properties, e.g., the oxidation and creep resistance [13-16].

As shown in Fig. 2, the oxidation behavior is significantly affected by the changes in matrix microstructure and volume fractions at different temperature regimes (between 800 and $1300{ }^{\circ} \mathrm{C}$ ). Due to the competing oxide formation of Mo 


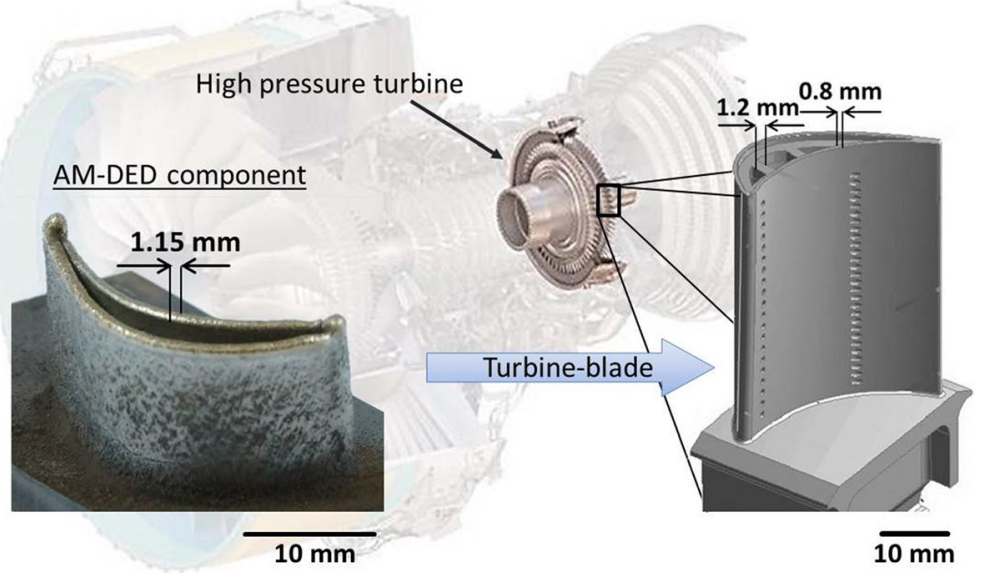

Fig. 1 Component manufactured via AM-DED process providing low wall thicknesses necessary for manufacturing turbine blades [11], FEM model of the turbine blade adapted from our previous work [12]

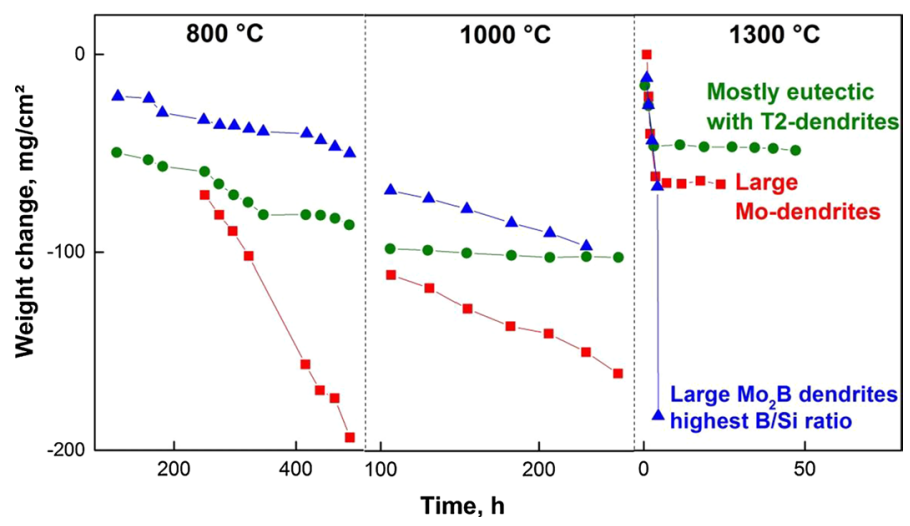

Fig. 2 Schematic of oxidation performance depending on the microstructure according to Supatarawanich [14]

oxides and silicate glasses, the multiphase alloys consisting of $\mathrm{Mo}, \mathrm{T} 2$ and $\mathrm{Mo}_{3} \mathrm{Si}$ display a poor oxidation resistance at $800{ }^{\circ} \mathrm{C}$ (so-called pesting) and $1000{ }^{\circ} \mathrm{C}$ compared to higher $\left(1300{ }^{\circ} \mathrm{C}\right)$ temperatures. Particularly at $800{ }^{\circ} \mathrm{C}$, the beginning formation of a boron-containing silica glass cannot provide a self-healing protective scale, additionally; the formation of voluminous Mo-oxides can lead to spallation of the scale.

Hence, alloys with a high volume fraction of large Mo-dendrites (Fig. 2 red curve) show the worst oxidation performance at $800{ }^{\circ} \mathrm{C}$. In contrast, a protective glass scale can be formed at $1300{ }^{\circ} \mathrm{C}$ even when containing about $50 \mathrm{vol} \%$ bcc Mo solid solution phase. Additionally, the importance of the $\mathrm{Mo}_{3} \mathrm{Si}$ phase as a supply 
of $\mathrm{Si}$ is demonstrated, since the alloy with the smallest volume fraction of $\mathrm{Mo}_{3} \mathrm{Si}$ (Fig. 2 blue curve) did not passivate at $1300{ }^{\circ} \mathrm{C}$. Hence, the boron content is too high resulting in a too low viscosity of the scale, lowering its protective effect. The near-eutectic microstructure (Fig. 2 green curve) provides a fine dispersion of T2, $\mathrm{Mo}$, and $\mathrm{Mo}_{3} \mathrm{Si}$, and thus displayed the best overall oxidation resistance for the temperatures tested [14]. Hence, according to Rioult et al. [17], the microstructure size scale has an important role as well. It was shown that microstructural refinement shortens the transient stage of oxidation and decreases the recession of $\mathrm{Mo}-\mathrm{Si}-\mathrm{B}$ alloys. The investigations showed that the $\mathrm{Mo}_{\mathrm{ss}}$ grains were the controlling factor in the duration of the transient period. Furthermore, the presence of nano-channels in the viscous glass formed above the $\mathrm{Mo}_{3} \mathrm{Si}$ phase was an important factor in overall mass loss. However, boron diffusion into the porous glass by a finely and homogeneously distributed T2 phase allows healing of the nano-channels by lowering the viscosity of the glass faster than for a coarse microstructure [17].

As the oxidation resistance in a wide temperature range is a decisive aspect for the potential use of AM DED Mo-Si-B alloys, the oxidation properties between 800 and $1300{ }^{\circ} \mathrm{C}$ were investigated in the present study. In order to evaluate the potential of the innovatively processed alloys, the results of cyclic oxidation were compared to the oxidation performance of other well investigated $\mathrm{Mo}-\mathrm{Si}-\mathrm{B}$ alloys (processed via powder metallurgy), which are chemically close and have similar microstructural features, i.e., larger primary $\mathrm{Mo}_{\mathrm{ss}}$ phases surrounded by a fine eutectic network.

\section{Material and Methods}

For additive manufacturing, the process of Directed Energy Deposition (DED) was chosen. As described in more detail [10], the solid raw materials (Mo $>99.95 \%$, $\mathrm{Si}>99.6 \%$ and $\mathrm{B}>99.4 \%$ purity) were molten and superheated in a crucible (inductive heating system) and subsequently atomized into powder/droplets (converging/diverging nozzle, using Ar gas flow), which then was sized to the target fraction $+45 /-90 \mu \mathrm{m}$. DED samples of approximately $10 \times 10 \times 5 \mathrm{~mm}^{3}$ in size were built out of the GA Mo-9Si-8B (at.\%) powder. A steel 1.4301 (AISI 304) served as substrate material. The process was performed using induction preheating of the processing plane to approximately $600{ }^{\circ} \mathrm{C}$. The laser beam source was a $2 \mathrm{~kW}$ diode laser, the beam diameter in the processing zone was $0.6 \mathrm{~mm}$. The build-up was performed with a power of $70 \mathrm{~W}$ and a velocity of $500 \mathrm{~mm} / \mathrm{min}$ through a continuous coaxial powder feed nozzle. An additional inert gas stream of 15 1/min Ar through the beam path improved the shielding from the surrounding atmosphere [10].

Microstructural investigations in the as-processed state and after oxidation treatment were carried out on samples cut via electrical discharge machining (EDM), subsequently embedded in a hot mounting polymer (Struers PolyFast). After wetgrinding from 500 down to 1200 grit, the specimens were polished with a $3 \mu \mathrm{m}$ and $1 \mu \mathrm{m}$ diamond suspension and finished by a colloidal silica suspension (OPS).

The microstructural observations were carried out by scanning electron microscopy (SEM-FEI ESEM XL30 FEG and Zeiss EVO 15 equipped with EDS). Additionally, electron backscatter diffraction (EBSD) analysis was performed to identify the phases 
using a Zeiss Merlin SEM equipped with a Nordlys EBSD camera and Aztec software package (Oxford Instruments).

Samples for cyclic oxidation tests were cut from the bulks in dimensions of $3 \times 3 \times 5 \mathrm{~mm}^{3}$. For cyclic oxidation certain temperature regimes and exposure times were chosen: (1) $800{ }^{\circ} \mathrm{C} / 100 \mathrm{~h}$, (b) $1100{ }^{\circ} \mathrm{C} / 100 \mathrm{~h}$ and (c) $1300{ }^{\circ} \mathrm{C} / 100 \mathrm{~h}$. In order to study the oxidation kinetics, the exposure of samples in static air at certain temperatures was typically carried out at defined cycles. For the AM DED Mo-9Si-8B alloy, the intermediate weighing of samples was carried out every 10 min during the first hour, every $60 \mathrm{~min}$ up to $8 \mathrm{~h}$ and finally every $24 \mathrm{~h}$ until the total exposure time $(100 \mathrm{~h})$ was reached. The experimental performance was carried out at the IfKorr (Institut für Korrosions- und Schadensanalyse, Magdeburg, Germany) using a LF15/14 Nabertherm furnace and for the PM reference alloy at Otto-von-Guericke University in a Thermconcept (HTL04/ 18) furnace.

Before placing the samples (three per temperature regime) within the pre-heated furnace, the initial weight, using an analytical balance (Satorius Cubis®, Satorius AG, Germany) with an accuracy of $0.0001 \mathrm{~g}$, and their dimensions were exactly determined. At the end of each cycle the samples were removed from the furnace, cooled down to room temperature under atmospheric conditions and carefully weighed to determine their mass loss after certain exposure times. Afterward the samples were re-exposed to the particular temperature regime described above. Finally, the macroscopic sample morphology and shape retention after finishing the total exposure time was recorded using stereomicroscopes (Olympus SZX7 and Zeiss Stemi 2000 C).

The resulting weight change curves were plotted vs. the exposure time, representing the predominant oxidation mechanisms. The oxidation rates were determined as the slope of the curves (in $\mathrm{mg} \cdot \mathrm{cm}^{-2} \cdot \mathrm{h}^{-1}$ ), respectively. Additionally, in order to gain a better understanding of the temperature-dependent oxidation mechanisms, the microstructural features of the oxidized samples were studied via SEM. Therefore, the samples were prepared as described above.

In order to evaluate the oxidation properties of the AM DED Mo-9Si-8B alloy, other Mo-Si-B alloys reported by Krüger et al. [9], Majumdar et al. [18, 19], Burk et al. [20], Berczik [5] as well as Jéhanno et al. [21] having the same chemical composition, were used for comparison. The reference alloys were processed via powder metallurgical processing, including the mechanical alloying for materials investigated in [9, 18-20] or the He-[5]/Ar-[21] gas atomization as the first step. Afterward the pre-alloyed powders were consolidated either by using a CIP (cold-isostatic pressing)-sinter-HIP (hot-isostatic pressing) processing [5, 9, 20], in the present work summarized as powder metallurgical route (PM) or by using the field assisted sintering technology (FAST) [18, 19].

\section{Results and Discussion}

\section{Microstructure After Processing}

Initially, the microstructure inside the DED-fabricated specimen was analyzed. The microstructure of the as-processed AM DED Mo-9Si-8B alloy is depicted in 
Fig. 3a representing a primarily solidified $\mathrm{Mo}_{\mathrm{ss}}$ (Mo solid solution) phase, partly grown dendritically in the fusion zones resulting from the layer-wise laser cladding process. Apart from the fusion zone, the heat affected zone, shown in Fig. 3b, depicts regions of primarily solidified $\mathrm{Mo}_{\mathrm{ss}}$ phases embedded in a $\mathrm{Mo}_{3} \mathrm{Si}-\mathrm{Mo}_{5} \mathrm{SiB}_{2}$ intermetallic matrix.

The individual phase fractions are illustrated in Fig. $3 \mathrm{c}$ where the phases are allocated to approximately $62 \%$ of $\mathrm{Mo}_{\mathrm{ss}}$ (colored in blue in Fig. 3c), $25 \%$ of $\mathrm{Mo}_{3} \mathrm{Si}$ (yellow) as well as $13 \%$ of $\mathrm{Mo}_{5} \mathrm{SiB}_{2}$ (red) and thus present a microstructure dominated by the $\mathrm{Mo}_{\mathrm{ss}}$ phase.

Microstructural investigations of the complete DED-fabricated specimen showed that the distinct zones may vary in terms of phase fractions due to complex solidification procedure during AM processing. Hence, a deviating microstructure can be seen in the marginal areas of the DED-produced specimen. Accordingly, besides of the microstructure shown, there can also appear rather eutectic regions than primary solidified $\mathrm{Mo}_{\mathrm{ss}}$ dendrites (Fig. 3d). As can be seen later at the oxidation performance at $1300{ }^{\circ} \mathrm{C} \mathrm{a} \mathrm{Mo}$ ss depleted microstructure is beneficial for oxidation resistance. So, further studies should focus on the compositional optimization of preliminary powders as well as on the optimization of DED process parameters.
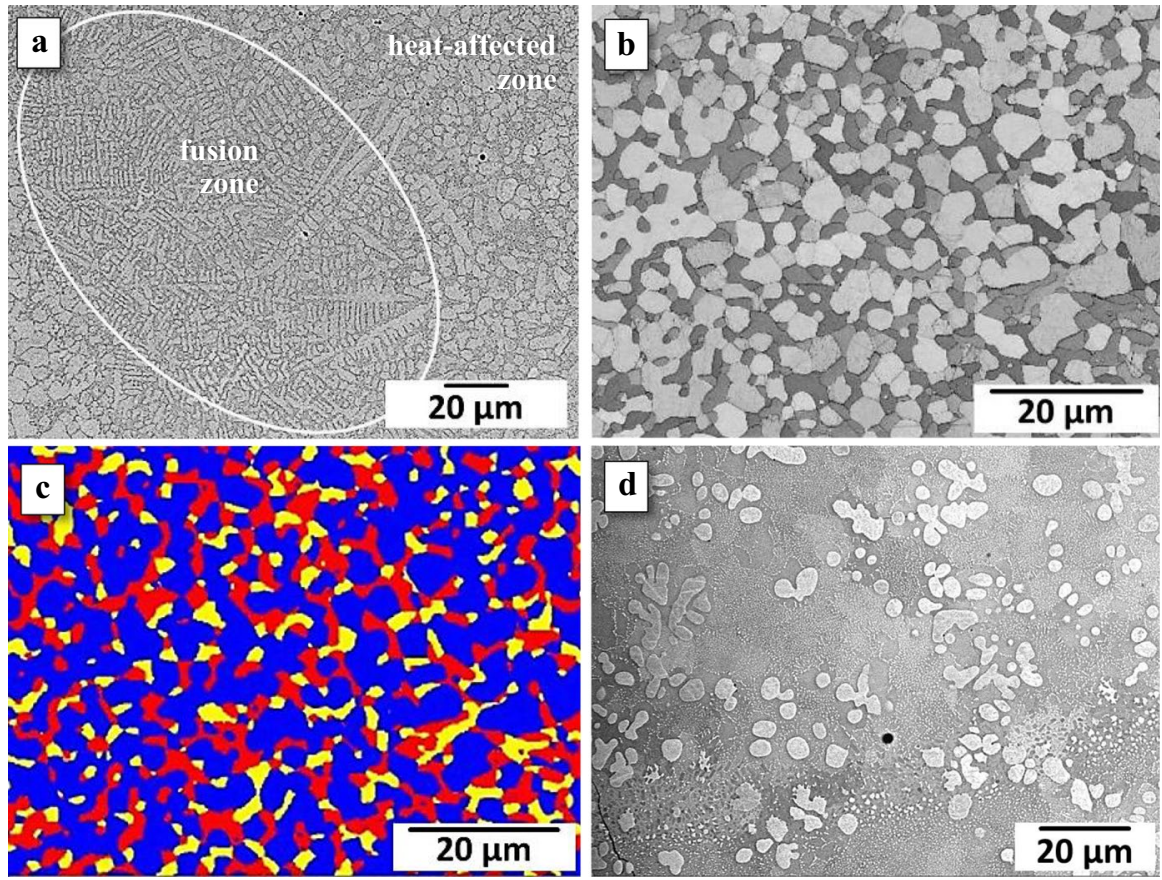

Fig. 3 Microstructure of the DED manufactured Mo-9Si-8B specimen a distinct zones (fusion and heataffected zone) resulting from the layer-wise laser cladding process $\mathbf{b}$ a typical section of the heat affected zone and its $\mathbf{c}$ phase identification via EBSD phase mapping: blue-Mo $\mathrm{Mo}_{\mathrm{ss}}$, yellow-Mo $\mathrm{Si}$ and $\mathrm{red}-\mathrm{Mo}_{5} \mathrm{SiB}_{2}$; d rather eutectic regions than primary solidified $\mathrm{Mo}_{\mathrm{ss}}$ dendrites (Color figure online) 
Comparing the microstructural constituents of AM DED Mo-9Si-8B to the reference alloys (see Table 1) it is obvious that the volume fraction of $\mathrm{Mo}_{\mathrm{ss}}$ as well as the grain size is significantly higher. This is not surprising since the primary gas atomized powders also have a high fraction of $\mathrm{Mo}_{\mathrm{ss}}$ by about $64 \%$. However, the microstructure inside the DED build is very homogeneous and the $\mathrm{Mo}_{\text {ss }}$ phase is favorably distributed as it is very close to a continuously distributed $\mathrm{Mo}_{\mathrm{ss}}$ phase. This shows that the previous gas atomization of the initial powders is not only beneficial for the powder flow and enables uniform build rates and enhanced adhesion between the single layers [22, 23], but also to create homogeneous microstructures.

\section{Cyclic Oxidation Response at $800^{\circ} \mathrm{C}$}

The temperature regime around $800{ }^{\circ} \mathrm{C}$ is the most challenging for $\mathrm{Mo}-\mathrm{Si}-\mathrm{B}$ alloys due to the "pesting" phenomenon [20] which is characterized by catastrophic oxidation caused by $\mathrm{MoO}_{3}$ evaporation. The results from the cyclic oxidation tests at $800{ }^{\circ} \mathrm{C}$ are shown in Fig. 4, representing an average curve of the three specimens tested for AM DED Mo-9Si-8B in comparison with PM Mo-9Si-8B reported by Burk et al. [20]. Both curves demonstrate the nonlinear mass loss with increasing exposure time. According to the oxidation mechanism map of Parthasarathy et al. [27], this represents a typical behavior for Mo-Si-B alloys in the specific temperature regime. This so-called pesting phenomenon is characterized by significant weight change right from the beginning followed by a slower linear mass loss rate. In case of AM DED Mo-9Si-8B, the mass loss is rather constant over the entire exposure time, offering a mass loss rate of $-1.18 \mathrm{mg} \cdot \mathrm{cm}^{-2} \cdot \mathrm{h}^{-1}$. Accordingly, while the PM Mo-9Si-8B [20] achieved a considerably lower mass loss after $\sim 30 \mathrm{~h}$, the weight change of the AM DED alloy continuously increases up to $-130 \mathrm{mg} \cdot \mathrm{cm}^{-2}$. As depicted by the macroscopic image (inset in Fig. 4a), the surface of the specimen is strongly oxidized so that the original sample shape is no longer preserved. As illustrated in Fig. 4b, the non-protective glass layer is very porous and cracked, resulting in the formation of a pronounced internal oxidation zone. An EDS element mapping of the layer, depicted in Fig. 4c, shows the formation of a porous $\mathrm{SiO}_{2}$ scale which enables further oxygen diffusion. It can be assumed, that due to the high fraction of primary solidified $\mathrm{Mo}_{\mathrm{ss}}$ phase in this alloy, but only $13 \%$ of $\mathrm{Mo}_{5} \mathrm{SiB}_{2}$ phase, no significant reservoir for the formation $\mathrm{B}_{2} \mathrm{O}_{3}$ is present. Hence, the silica glass is unable to form a self-healing protective scale at intermediate temperatures.

Regardless of the alloy composition, the amount of $\mathrm{Mo}_{\mathrm{ss}}$ phase is not the only factor that influences the oxidation performance; the phase distribution and microstructure size scale has an important role as well. Even if the glass quickly covers the surface of the samples, the $\mathrm{Mo}_{\mathrm{ss}}$ grains are the controlling factor in terms of the duration of the transient period, as reported by Rioult et al. [17]. Hence, compared with PM Mo-9Si-8B, the oxidation resistance of the AM DED processed alloy is strongly affected by its coarser $\mathrm{Mo}_{\mathrm{ss}}$ grain size and lower amount of T2 phase. 


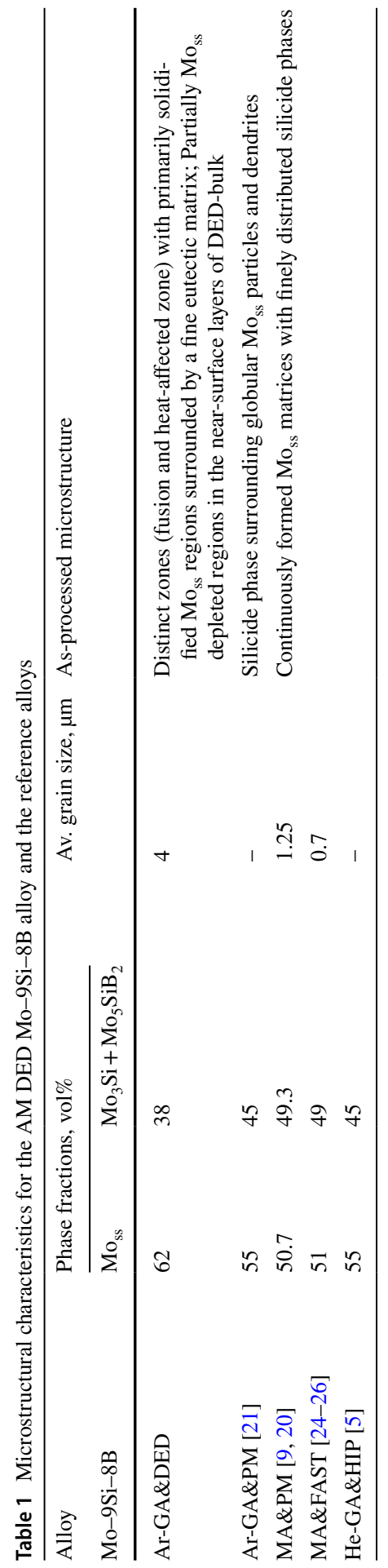



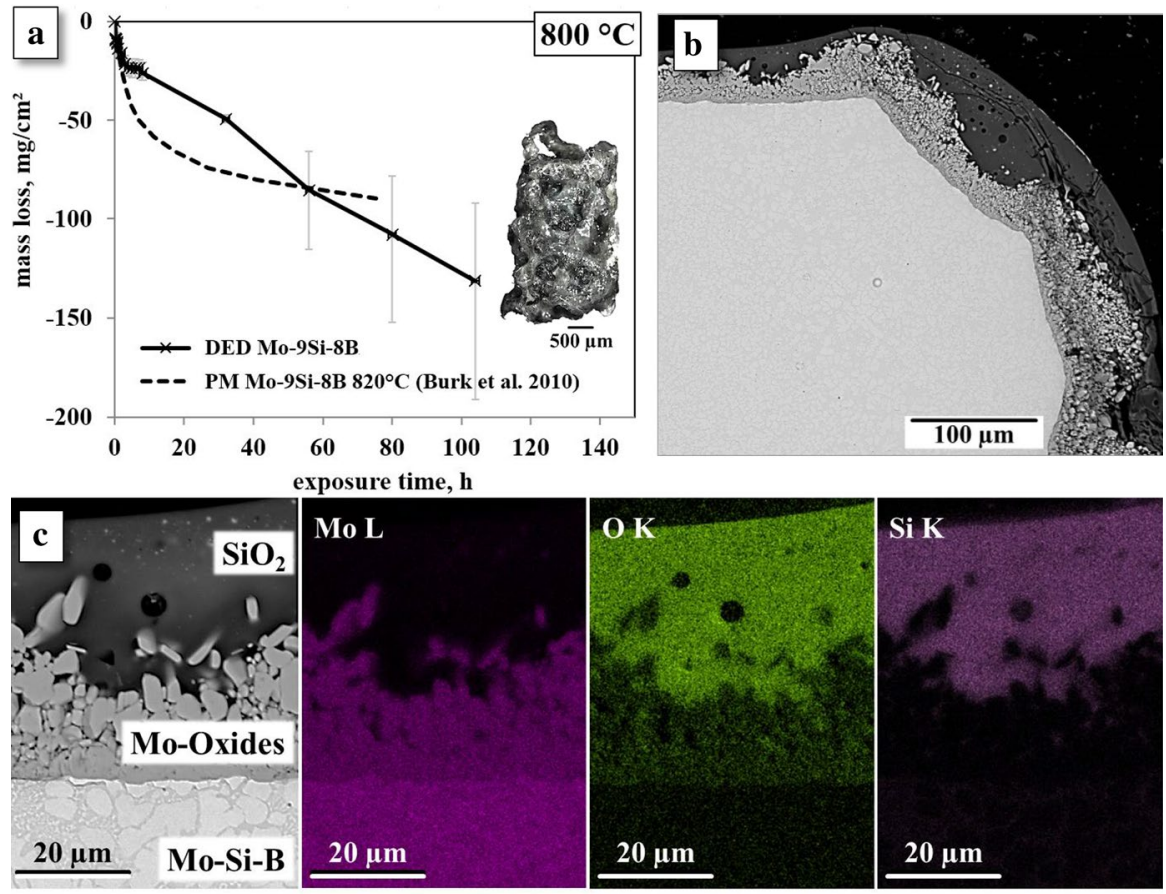

Fig. 4 a Mass loss curve of the AM DED Mo-9Si-8B alloy oxidized at $800{ }^{\circ} \mathrm{C}$ including a macroscopic image of the specimen after reaching the total exposure time of $100 \mathrm{~h}$; in comparison with PM Mo-9Si$8 \mathrm{~B}$ reported by Burk et al. [20]; layer formation after total exposure $\mathbf{b}$ at the edge of the specimen after exposure for $100 \mathrm{~h}$ and $\mathbf{c}$ EDS mappings for different elements indicating a layer of Mo oxide at the substrate interface, as also shown by Burk et al. [20, 28], and the porous $\mathrm{SiO}_{2}$ scale

\section{Cyclic Oxidation Response at $1100^{\circ} \mathrm{C}$}

Understanding the oxidation performance at $1100{ }^{\circ} \mathrm{C}$ is very important since it displays a critical temperature of current state-of-the-art Ni-based superalloys used in gas turbines, for which $\mathrm{Mo}-\mathrm{Si}-\mathrm{B}$ alloys are potential substitutes. Accordingly, many superalloy oxidation studies are done at this temperature. In contrast to the oxidation mechanisms at $800{ }^{\circ} \mathrm{C}$ accompanied with high initial mass losses, the oxidation behavior changes when the samples are exposed to air at higher temperatures. As depicted in Fig. 5a, after an initial mass loss during the first hours, only small mass losses were observed for the PM and AM DED Mo-9Si-8B alloys. In case of PM Mo-9Si-8B, the fine scaled microstructure features small diffusion paths for the reaction of $\mathrm{O}_{2}$ with the constituents $\mathrm{Mo}_{\text {ss }}, \mathrm{Mo}_{3} \mathrm{Si}$ or $\mathrm{Mo}_{5} \mathrm{SiB}_{2}$, so that a protective borosilicate layer can be formed very rapidly. However, compared with the PM alloys, AM DED Mo-9Si-8B shows a higher initial mass loss until reaching the plateau-like behavior which results from the slightly coarser microstructure, especially the coarser $\mathrm{Mo}_{\mathrm{ss}}$ phase (Fig. 5b), as also indicated by Jéhanno et al. and Rioult et al. [17, 21]. However, 

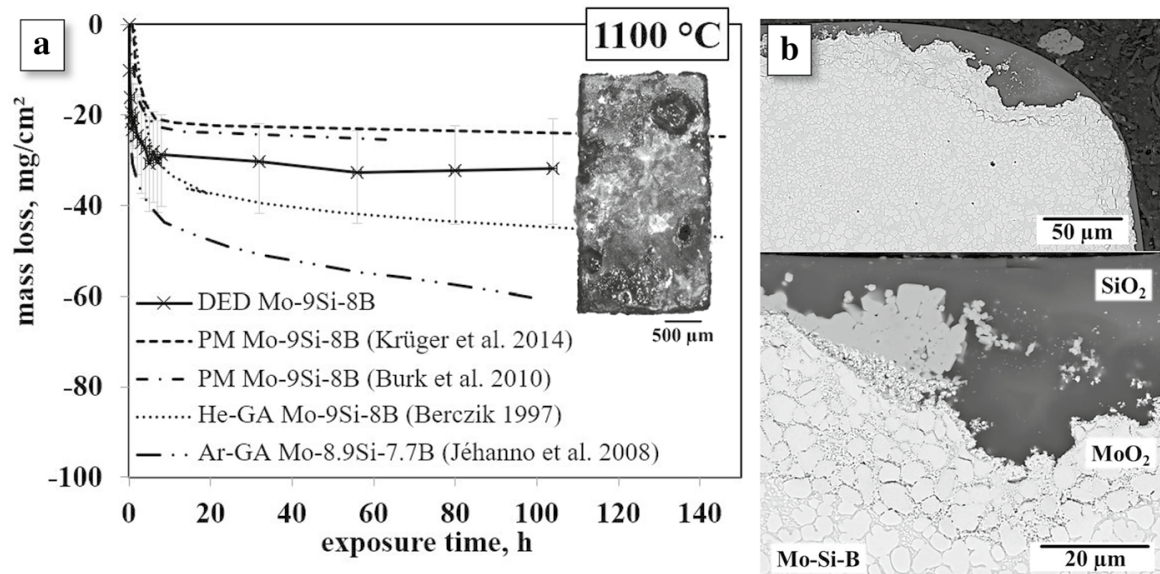

Fig. 5 a Mass loss curve of the AM DED Mo-9Si-8B alloy oxidized at $1100{ }^{\circ} \mathrm{C}$ including a macroscopic image of the specimen after reaching the total exposure time of $100 \mathrm{~h}$; in comparison to PM Mo-9Si-8B by Krüger et al. [9] and Burk et al. [20] as well as He-GA Mo-9Si-8B investigated by Berczik [5] and Ar-GA and PM Mo-8.9Si-7.7B by Jéhanno et al. [21] and b cross-sectional BSE image showing the interface of different oxide layers with the Mo-9Si-8B alloy substrate oxidized at $1100{ }^{\circ} \mathrm{C}$

even if the microstructure of the He-GA Mo-9Si-8B alloy is expected to be as fine grained as the PM alloys, its oxidation behavior is worse due to the larger primary $\mathrm{Mo}_{\mathrm{ss}}$ phase regions.

As depicted by the macroscopic image, the present alloy maintained its original geometry reasonably well (inset in Fig. 5a), due to the formation of the protective $\mathrm{SiO}_{2}-\mathrm{B}_{2} \mathrm{O}_{3}$ scale. As illustrated in Fig. $5 \mathrm{~b}$, the oxide scale formed continuously over the sample surface but with varying scale thicknesses. While the general scale thickness is about $5 \mu \mathrm{m}$, the edges of the sample show thicknesses up to $40 \mu \mathrm{m}$. Those varying scale thicknesses result from the coarser phases of $\mathrm{Mo}_{\mathrm{ss}}$, enlarging the diffusion paths for the formation of a protective scale.

\section{Cyclic Oxidation Response at $1300^{\circ} \mathrm{C}$}

According to the oxidation mechanism map by Parthasarathy et al. [27], the oxidation behavior at $1300{ }^{\circ} \mathrm{C}$ is characterized by an initial period of slight mass loss followed by passivation in which almost no further change in weight is measured, as shown in case of PM Mo-9Si-8B [18].

Generally, it is suggested that at $1300{ }^{\circ} \mathrm{C}, \mathrm{B}_{2} \mathrm{O}_{3}$ helps to cover the surface by fluxing silica, but it begins to evaporate soon after the scale has covered the surface, resulting in a low B- containing silica. It was also reported, that the viscosity of the glassy silica changes drastically with small modifications in $\mathrm{B}_{2} \mathrm{O}_{3}$ content [27]. Thus, the low B-containing silica at $1300{ }^{\circ} \mathrm{C}$ probably has a sufficiently high viscosity to reduce significantly the $\mathrm{MoO}_{3}$ permeation. Additionally, the diffusivity of oxygen in B-silica is also slowed down significantly with lowered B-content; thus slower scale (silica) growth kinetics is predicted. 
As depicted in Fig. 6, in case of the AM DED alloy, two types of oxidation behavior were observed. One sample, the AM DED Mo-9Si-8B (1), which represents the microstructure at the near-surface layer of the DED sample, showed almost no mass loss, whereas other samples which were taken from the typical microstructure inside the DED build (depicted as average curve AM DED Mo-9Si-8B (2\&3)), showed a strong mass loss with significant oxidation effects on the surface. Figure 7 illustrates the differences in microstructure which are responsible for the different behaviors of AM Mo-Si-B samples, which correspond to the two types of microstructures already described in Fig. 3, i.e., for typical sections inside a built structure and the outer regions of a DED build.

As described earlier, primarily solidified $\mathrm{Mo}_{\mathrm{ss}}$ phase is partly grown dendritically in the fusion zones resulting from the layer-wise laser cladding process. Apart from that, the heat affected zone, shown in Fig. 3b, depicts regions of primarily solidified $\mathrm{Mo}_{\text {ss }}$ phases embedded in a $\mathrm{Mo}_{3} \mathrm{Si}-\mathrm{Mo}_{5} \mathrm{SiB}_{2}$ intermetallic matrix. Additionally, the marginal zones may vary in their phase composition so that can also appear rather eutectic regions than primary solidified $\mathrm{Mo}_{\mathrm{ss}}$ dendrites. And this is the case for the alloy AM DED Mo-9Si-8B (1) which represents a reduced amount (around $45 \mathrm{vol} \%$ ) of primarily solidified $\mathrm{Mo}_{\mathrm{ss}}$ dendrites as well as binary $\mathrm{Mo}_{3} \mathrm{Si}-\mathrm{Mo}_{5} \mathrm{SiB}_{2}$ and ternary $\mathrm{Mo}_{\mathrm{ss}}-\mathrm{Mo}_{3} \mathrm{Si}-\mathrm{Mo}_{5} \mathrm{SiB}_{2}$ eutectic regions which positively affect the formation of a uniform self-healing Si-B-O glass layer (Fig. 7). The glass layer formed continuously with a thickness of around $10 \mu \mathrm{m}$. In contrast, the alloys AM DED Mo-9Si-8B (2\&3) suffer from their higher amount of $\mathrm{Mo}_{\mathrm{ss}}$ phase resulting in high mass losses. These observations presented here correspond very well to those of Supatarawanich et al. [14], showing that the near-eutectic microstructure (Fig. 2 green curve) provides a fine dispersion of $\mathrm{T} 2, \mathrm{Mo}$, and $\mathrm{Mo}_{3} \mathrm{Si}$, and thus displayed the best overall oxidation resistance for the temperatures tested. Hence, the AM DED Mo-9Si-8B specimen show no mass loss, which means that the original sample shape has been preserved (Fig. 6 curve (1) and respective micrograph in Fig. 7).

In contrast the alloys AM DED Mo-9Si-8B (2\&3) show a significant mass loss of around $-170 \mathrm{mg} \cdot \mathrm{cm}^{-2}$ right at the beginning of exposure, which stabilizes very quickly in a plateau-like behavior. As can be seen in Fig. 7, the

Fig. 6 Mass loss curves of AM DED Mo-9Si-8B specimen oxidized at $1300{ }^{\circ} \mathrm{C}$ including macroscopic images of the specimen after reaching the total exposure time of $100 \mathrm{~h}$; in comparison to PM Mo-9Si-8B reported by Majumdar et al. [18] and Ar-GA and PM Mo-8.9Si7.7B (at $1315^{\circ} \mathrm{C}$ ) by Jéhanno et al. [21]

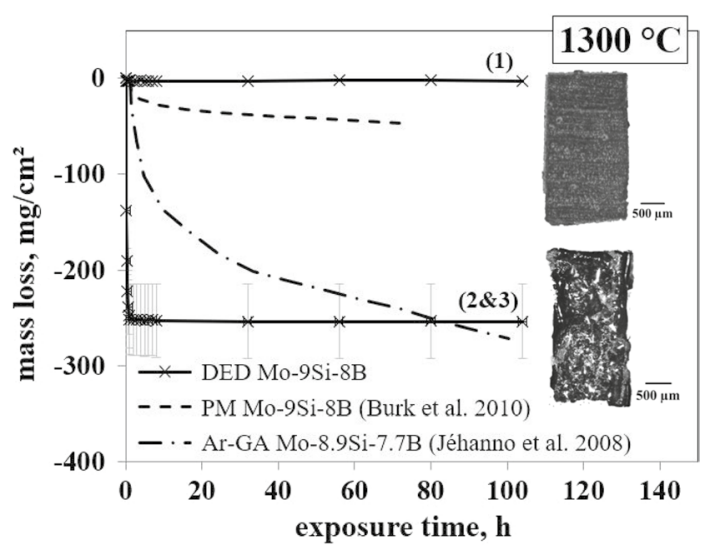



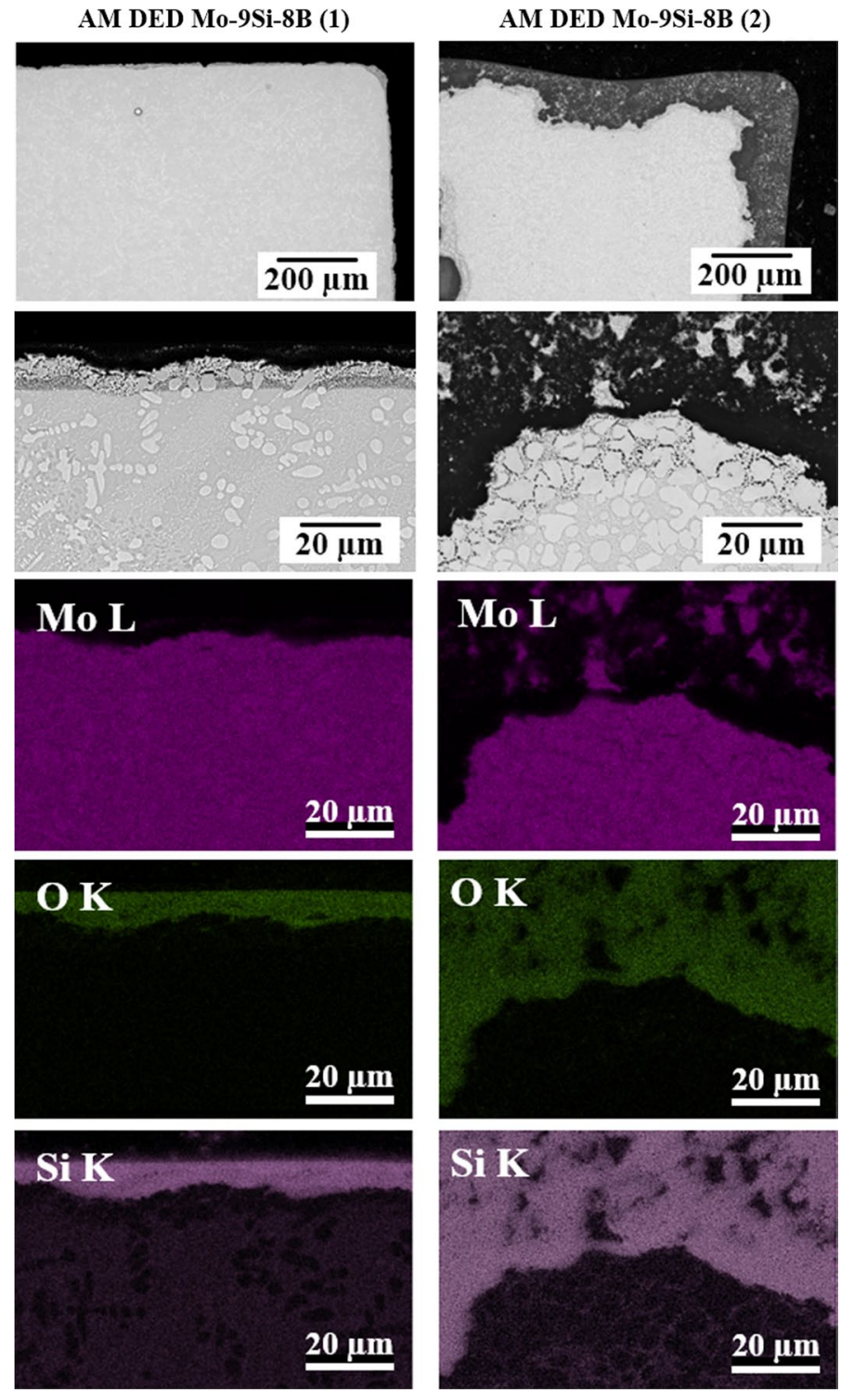

Fig. 7 Layer formation after total exposure $(100 \mathrm{~h})$ at $1300{ }^{\circ} \mathrm{C}$ for AM DED Mo-9Si-8B for specimen (1) and (2) as represented in Fig. 6; including EDS maps for the elements Mo, O, Si

microstructure is again dominated by the high amount of primarily solidified $\mathrm{Mo}_{\mathrm{ss}}$ phases, which initially hinders the rapid formation of the glass layer. Afterward an irregular $\mathrm{SiO}_{2}$ layer formed protecting the sample from further oxidation. The layer thickness is 10 times higher (around $100 \mu \mathrm{m}$ ) than for sample (1) but therefore shows a much higher porosity. 
The observed divergent behavior is due to the local microstructural inhomogeneities resulting from DED processing. It must be investigated in future work, how modified processing parameters will affect the microstructure-property relationship.

\section{Summary}

In the present work, the technically relevant alloy composition of Mo-9Si-8B was successfully processed via AM DED. Apart from the laser cladding zones resulting typically from the layer wise cladding process, a homogeneous microstructure formed. It consists of primarily solidified $\mathrm{Mo}_{\mathrm{ss}}$ phases embedded in a silicide-dominated matrix of $\mathrm{Mo}_{3} \mathrm{Si}-\mathrm{Mo}_{5} \mathrm{SiB}_{2}$ and $\mathrm{Mo}_{\mathrm{ss}}-\mathrm{Mo}_{3} \mathrm{Si}_{-}-\mathrm{Mo}_{5} \mathrm{SiB}_{2}$ eutectics. The focus of the present work is set on the oxidation mechanisms and scale formation behavior in this AM DED Mo-9Si-8B alloy which were studied in the temperature range of $800-1300{ }^{\circ} \mathrm{C}$.

At $800{ }^{\circ} \mathrm{C}$, the typical "pesting" behavior occurs resulting in high mass losses. Compared with PM Mo-9Si-8B, the oxidation resistance of the AM DED processed alloy suffers from its coarser grain size of the $\mathrm{Mo}_{\mathrm{ss}}$ phase and lower amount of silicide phases. Significantly lower mass losses occur at $1100{ }^{\circ} \mathrm{C}$ due to the changing oxidation mechanisms. After initial mass losses about $-30 \mathrm{mg} / \mathrm{cm}^{2}$ a protective $\mathrm{SiO}_{2}-\mathrm{B}_{2} \mathrm{O}_{3}$ scale formed continuously over the sample surface, protecting the sample from further oxidation accompanied with reaching a plateau-like behavior in the mass change curves. At $1300{ }^{\circ} \mathrm{C}$, two different oxidation performances were observed, which could be explained by the locally different microstructures. The specimen AM DED Mo-9Si-8B (1) benefits from the reduced amount of primary $\mathrm{Mo}_{\text {ss }}$ phases in combination with ultra-fine binary and ternary eutectics. In contrast, the AM DED Mo-9Si-8B (2) suffers from significant mass loss $\left(-170 \mathrm{mg} \cdot \mathrm{cm}^{-2}\right)$ right at the beginning of exposure, which is caused by the high amount of larger $\mathrm{Mo}_{\mathrm{ss}}$ regions hindering the rapid layer formation.

Despite from the divergent behavior of samples taken from the inner and outer region of the AM build observed at $1300{ }^{\circ} \mathrm{C}$, the DED alloy follows the well-known oxidation schematic of Mo-Si-B alloys. It is assumed that local microstructural deviations could be reduced by optimizing the DED process. However, in case of DED Mo-9Si-8B the process-dependent depletion of the $\mathrm{Mo}_{\mathrm{ss}}$ phase in the outer layer of the built samples supports the oxidation protection of the bulk.

Acknowledgements The presented research was funded by the cooperative BMBF project „LextrA" (03XP0094). Some oxidation experiments were performed within the DFG project "Active oxidation protection coatings for Mo-Si-B high temperature materials" (DFG nb. 317275772). We thank Dr. E. Wessel (Research Center Jülich, Germany) for his assistance with the SEM and EBSD analysis of the initial state of the alloy.

Funding Open Access funding enabled and organized by Projekt DEAL.

Open Access This article is licensed under a Creative Commons Attribution 4.0 International License, which permits use, sharing, adaptation, distribution and reproduction in any medium or format, as long as you give appropriate credit to the original author(s) and the source, provide a link to the Creative Commons licence, and indicate if changes were made. The images or other third party material in this article 
are included in the article's Creative Commons licence, unless indicated otherwise in a credit line to the material. If material is not included in the article's Creative Commons licence and your intended use is not permitted by statutory regulation or exceeds the permitted use, you will need to obtain permission directly from the copyright holder. To view a copy of this licence, visit http://creativecommons.org/licen ses/by/4.0/.

\section{References}

1. W.O. Soboyejo, T.S. Srivatsan, Advanced Structural Materials: Properties, Design Optimization, and Applications, CRC Press, Boca Raton, 2006.

2. G. Hasemann, D. Kaplunenko, I. Bogomol, M. Krüger, Near-Eutectic Ternary Mo-Si-B Alloys: Microstructures and Creep Properties, JOM. 68 (2016) 2847-2853. doi:https://doi.org/10.1007/ s11837-016-2073-0.

3. A.P. Alur, N. Chollacoop, K.S. Kumar, Creep effects on crack growth in a Mo-Si-B alloy, Acta Mater. 55 (2007) 961-974. doi:https://doi.org/10.1016/j.actamat.2006.09.028.

4. K. Yoshimi, S. Nakatani, N. Nomura, S. Hanada, Thermal expansion, strength and oxidation resistance of Mo/Mo5SiB2 in-situ composites at elevated temperatures, Intermetallics. 11 (2003) 787794. doi:https://doi.org/10.1016/S0966-9795(03)00073-6.

5. D.M. Berczik, U.S. Patents 5,595,616 und 5,693,156 (1997).

6. S.H. Ha, K. Yoshimi, K. Maruyama, R. Tu, T. Goto, Compositional regions of single phases at $1800^{\circ} \mathrm{C}$ in Mo-rich Mo-Si-B ternary system, Mater. Sci. Eng. A. 552 (2012) 179-188. doi:https:// doi.org/10.1016/j.msea.2012.05.028.

7. J.H. Schneibel, C.T. Liu, D.S. Easton, C.A. Carmichael, Microstructure and mechanical properties of Mo - Mo3Si - Mo5 SiB2 silicides, Mater. Sci. Eng. A. 261 (1999) 78-83.

8. J.H. Schneibel, P.F. Tortorelli, R.O. Ritchie, J.J. Kruzic, Optimization of Mo-Si-B intermetallic alloys, Metall. Mater. Trans. A. 36 (2005) 525-531. doi:https://doi.org/10.1007/s11661-005-0166-4.

9. M. Krüger, P. Jain, K.S. Kumar, M. Heilmaier, Correlation between microstructure and properties of fine grained Mo-Mo3Si-Mo5SiB2 alloys, Intermetallics. 48 (2014) 10-18. doi:https://doi.org/10. 1016/j.intermet.2013.10.025.

10. J. Schmelzer, S.K. Rittinghaus, A. Weisheit, M. Stobik, J. Paulus, K. Gruber, E. Wessel, C. Heinze, M. Krüger, Printability of gas atomized Mo-Si-B powders by laser metal deposition, Int. J. Refract. Met. Hard Mater. 78 (2019) 123-126. doi:https://doi.org/10.1016/j.ijrmhm.2018.08.016.

11. E. Alliance, https://www.enginealliance.com/gp7200/ (2020).

12. O. Kauss, H. Tsybenko, K. Naumenko, S. Hütter, M. Krüger, Structural analysis of gas turbine blades made of Mo-Si-B under transient thermo-mechanical loads, Comput. Mater. Sci. 165 (2019) 129-136.

13. M. Krüger, J. Schmelzer, D. Fichtner, C. Heinze, Y. Küsters, S.K. Rittinghaus, A. Weisheit, R. Heinz, L. Gerking, K. Gruber, S. Schmigalla, S. Schultze, Recent advances in additive manufacturing of Mo-Si-B alloys - A status report on the cooperative project LextrA - A s, IOP Conf. Ser. Mater. Sci. Eng. 882 (2020). doi:https://doi.org/10.1088/1757-899X/882/1/012011.

14. V. Supatarawanich, D.R. Johnson, C.T. Liu, Effects of microstructure on the oxidation behavior of multiphase Mo-Si-B alloys, Mater. Sci. Eng. A. 344 (2003) 328-339. doi:https://doi.org/10.1016/ S0921-5093(02)00446-X.

15. V. Supatarawanich, D.R. Johnson, C.T. Liu, Oxidation behavior of multiphase Mo-Si-B alloys, Intermetallics. 12 (2004) 721-725. doi:https://doi.org/10.1016/j.intermet.2004.02.011.

16. P. Jain, K.S. Kumar, Tensile creep of Mo - Si - B alloys, Acta Mater. 58 (2010) 2124-2142. doi:https://doi.org/10.1016/j.actamat.2009.11.054.

17. F.A. Rioult, S.D. Imhoff, R. Sakidja, J.H. Perepezko, Transient oxidation of Mo-Si-B alloys: Effect of the microstructure size scale, Acta Mater. 57 (2009) 4600-4613. doi:https://doi.org/10.1016/j. actamat.2009.06.036.

18. S. Majumdar, B. Gorr, H.J. Christ, D. Schliephake, M. Heilmaier, Oxidation mechanisms of lanthanum-alloyed Mo-Si-B, Corros. Sci. 88 (2014) 360-371. doi:https://doi.org/10.1016/j.corsci.2014. 07.058. 
19. S. Majumdar, D. Schliephake, B. Gorr, H.J. Christ, M. Heilmaier, Effect of yttrium alloying on intermediate to high-temperature oxidation behavior of Mo-Si-B alloys, Metall. Mater. Trans. A Phys. Metall. Mater. Sci. 44 (2013) 2243-2257. doi:https://doi.org/10.1007/s11661-012-1589-3.

20. S. Burk, B. Gorr, V.B. Trindade, H.J. Christ, Effect of Zr addition on the high-temperature oxidation behaviour of Mo-Si-B alloys, Oxid. Met. 73 (2010) 163-181. doi:https://doi.org/10.1007/ s11085-009-9175-9.

21. P. Jéhanno, M. Böning, H. Kestler, M. Heilmaier, H. Saage, M. Krüger, Molybdenum alloys for high temperature applications in air, Powder Metall. 51 (2008) 99-102. doi:https://doi.org/10.1179/ 174329008 X313379.

22. T. Mukherjee, J.S. Zuback, A. De, T. DebRoy, Printability of alloys for additive manufacturing, Sci. Rep. 6 (2016) 1-8. doi:https://doi.org/10.1038/srep19717.

23. D. Schulze, Pulver und Schüttgüter, 2014. doi:https://doi.org/10.1007/978-3-642-53885-8.

24. C. Hochmuth, D. Schliephake, R. Völkl, M. Heilmaier, U. Glatzel, Influence of zirconium content on microstructure and creep properties of Mo-9Si-8B alloys, Intermetallics. 48 (2014) 3-9. doi:https://doi.org/10.1016/j.intermet.2013.08.017.

25. M. Krüger, D. Schliephake, P. Jain, K.S. Kumar, Effects of Zr Additions on the Microstructure and the Mechanical Behavior of PM Mo-Si-B Alloys, JOM. 65 (2013) 301-306. doi:https://doi.org/10. 1007/s11837-012-0475-1.

26. J. Becker, Development of Density Reduced Mo-Si-B Alloys, Dr. Thesis. (2019), p. 117. https://doi. org/10.25673/32314.

27. T.A. Parthasarathy, M.G. Mendiratta, D.M. Dimiduk, Oxidation mechanisms in Mo-reinforced Mo5SiB2 (T2)-Mo3Si alloys, Acta Mater. 50 (2002) 1857-1868.

28. S. Burk, B. Gorr, H.J. Christ, High temperature oxidation of Mo-Si-B alloys: Effect of low and very low oxygen partial pressures, Acta Mater. 58 (2010) 6154-6165. doi:https://doi.org/10.1016/j.actam at.2010.07.034.

Publisher's Note Springer Nature remains neutral with regard to jurisdictional claims in published maps and institutional affiliations. 